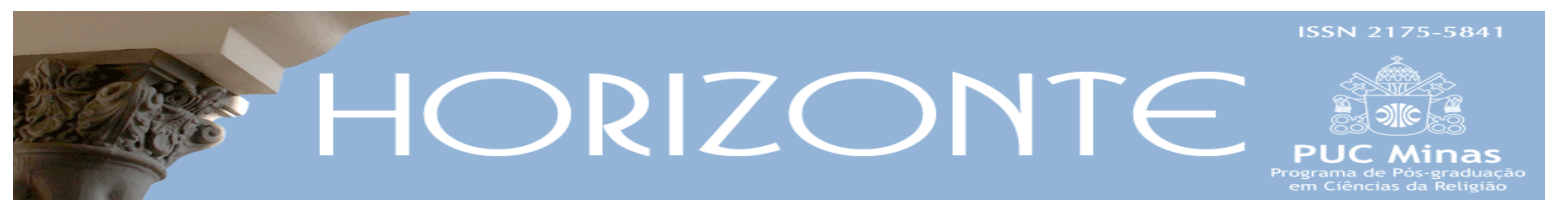

Temática Livre - Artigo Original

(c) (i) DOI - 10.5752/P.2175-5841.2019v17n52p300

\title{
Entre a parábola e o conto: Jesus, um contador de histórias
}

\author{
From the parable to the short story: Jesus, a storyteller
}

\author{
Levi Fernandes Leonido da Silva * \\ João Bartolomeu Rodrigues ** \\ Elsa Gabriel Morgado ***
}

\begin{abstract}
Resumo
Nesta investigação, propomo-nos demonstrar que Jesus foi um verdadeiro contador de histórias. A narrativa lucana conhecida tradicionalmente por parábola do Filho pródigo (LC 15, 11-32) não é propriamente uma parábola, pois assume os contornos formais de um conto, podendo-se nela encontrar as caraterística centrais do género literário "o conto". Nela encontramos propriedades configuradoras da sua individualização como género: a conclusão moralizante de uma história fechada, com princípio, meio e fim; a concentração de espaço, tempo e reduzido número de personagens; a curta extensão sintagmática, mas sempre extensa comparada com a das parábolas. Em suma, concluímos que estamos perante um verdadeiro e extraordinário conto. Há, no entanto, outras narrativas evangélicas que pelas suas características se assemelham à do Filho pródigo. Podemos assim identificar a do Administrador infiel (Lc 16, 1-8), a narrativa dos Vinhateiros homicidas (Lc 20,9, 19), a das Moedas de ouro (Lc 19, 11-27) e respetivos paralelos de Mt (25, 14), que se revestem de característica muito semelhantes às do Filho pródigo, apesar de muito menos desenvolvidas e que, no fundo, as consideramos como sendo embriões de contos.
\end{abstract}

Palavras-chave: contista; conto literário; filho pródigo; evangelho.

\begin{abstract}
In this study, we intend to demonstrate that Jesus was a real Storyteller. The Lucan narrative traditionally known as parable of the Prodigal son (Luke 15: 11-32), is not technically a parable, due to the fact that assumes the formal shape of a short story, in which one can find all the characteristic of such literary genre " the short story". In it is possible to find his configuring properties in his individualization as a genre: the moral conclusion of a closed story, with a beginning, a middle and an end; the concentration of space, time and a reduced number of characters; the short syntagmatic extension, but always extensive when comparing with short stories. In short, it is possible to conclude that we are before a real and extraordinary short story. There are, however, other gospel narratives whose characteristics are similar to the prodigal son. We can thus identify the Unfaithful administrator (Luke 16: 1-8), the narrative of the Winemakers murderers (Luke 20: 9, 19), the Gold coins (Luke 19: 11-27) and the respective parallelisms by Matthew (25, 14), which are of very similar characteristics to the Prodigal son, even though they are much less developed. We characterize them as short stories embryos.
\end{abstract}

Keywords: storyteller; short story; prodigal son; gospel.

Artigo submetido em 13 de janeiro de 2018 e aprovado em 29 de abril de 2019.

* Doutor em Educação pela Universidade de Salamanca - USAL. Professor da Escola de Ciências Humanas e Sociais da UTAD. País de origem: Portugal. E-mail: levileon@utad.pt

** Doutor em Ciências da Educação. Professor na Universidade de Trás-os-Montes e Alto Douro. País de origem: Portugal. E-mail: jbarto@utad.pt

*** Doutora em Ciências da Educação pela Universidade de Trás-os-Montes e Alto Douro. Membro da International Study Association on Teachersand Teaching (ISATT), University of Reading, UK. País de origem: Portugal. E-mail: elsagmorgado@gamil.com 


\section{Introdução}

Se entrarmos numa biblioteca moderna facilmente verificamos que a classificação dos livros obedece a um critério - em princípio, o da Classificação Decimal Universal (CDU). Implicitamente afirmamos que a pessoa que presidiu à classificação de um determinado livro, consciente ou inconscientemente, determinou de algum modo, o género literário a que pertence a obra que tratou: ficção, história, poesia, drama, biografia etc.

Hoje a literatura já não defende como em épocas anteriores a distinção de géneros, chegando mesmo haver quem escreva que "persistir em se ocupar dos géneros pode parecer hoje em dia passatempo ocioso, senão anacrónico" (TORODOV, 1978, p. 45). Apesar disso, consideramos pertinente o estudo das formas tipológicas nos Evangelhos.

Sem entrarmos, detalhadamente, na questão da classificação das tipologias textuais, pretendemos afirmar que "as classificações já propostas dos géneros são em número infinito" (DUCROT; TODOROV 1991, p. 190). Por isso, a fase da determinação das formas ainda não terminou, está em aberto.

Dibelius (1984, p. 13), refere que "toda la historia da literatura se reduce a determinar la historia de las formas”, esta afirmação é válida para todo o tipo de escritos, mas ganha uma importância peculiar quando se trata de obras, cuja personalidade do seu autor é um elemento secundário. Nas tradições populares, as peculiaridades do poeta ou do narrador são insignificantes; diz o nosso adágio português que "quem conta um conto aumenta um ponto". Queremos afirmar que nas tradições populares

la transmisión de tradiciones, los cambios o ampliaciones de las mismas son ya de suyo una auténtica creación, producto de la actividad de muchísimos autores que personalmente no buscan una finalidad literaria propiamente dicha. En tales tradiciones tiene mucha más importancia la forma, cuyo origen se sitúa en el impulso de las necesidades prácticas o que es transmitida por costumbre o tradición. (DIBELIUS, 1984, p. 13). 
Esta afirmação tem tanto mais valor quanto mais nos situamos no âmbito da literatura menor. Entende-se por literatura menor o "estádio inferior da literatura que não conta com recursos artístico literários, nem está determinado pelas orientações típicas dos escritores qualificados como obras artísticas, nem se dirige ao mesmo público que estes” (DIBELIUS, 1984, p. 13).

Dibelius (1984) é perentório ao inserir os Evangelhos sinópticos dentro da literatura menor.

Hoy día resulta bastante fácil distinguir entre literatura menor y escritos de carácter privado, ya que el mismo hecho de la publicación impresa y la posterior comercialización establece una cierta distinción entre tratados literarios menores - calendarios populares, folletos de sociedades, cuadernos novelescos y escritos personales - y los textos policopiados o incluso impresos ad instar manuscripti. En el caso de las obras antiguas no es tan fácil determinar con seguridade el procedimiento seguido en su publicación. Pensemos por ejemplo en las diversas copias de una carta de Pablo destinadas a un público estrictamente cristiano: cuándo traspasaron tales escritos los límites de la literatura privada para convertirse en literatura menor? Es muy difícil decir si muchos de los escritos del Nuevo Testamento estaban pensados para ser publicados, es decir, para circular entre el grupo reducido de lectores, destinatario habitual de la literatura menor. (DIBELIUS, 1984, p. 13-14).

No entanto, exclui a hipótese que os apresenta como escritos privados. Eles destinavam-se à publicação, embora os seus destinatários fossem muito escassos e bem mais modesto do que os outros.

In grosso modo, podemos afirmar que a determinação dos géneros, do Antigo Testamento, foi um princípio implicitamente reconhecido desde o final século I d. C. (RAIMOND; FITZMYER; MORPHY, 1972). A TaNaKe hebraica foi a primeira classificação do Antigo Testamento: Tôráh, Nebiim e Ketubim, ou seja, a Lei, os Profetas e Outros Escritos. Desde então longo caminho se percorreu até aos nossos dias.

Porém, foi a partir da primeira Grande Guerra que teve início a fase das descobertas para a crítica das formas. André Jolles, na sua famosa obra Formas simples (1972) pesquisou e recenseou certas formas de linguagem ${ }^{1}$, como a lenda, o

${ }^{1}$ Não fazemos referência às formas pré-literárias. Tal estudo cairia fora do âmbito da nossa investigação. 
enigma, a sentença, o conto, a piada e procurou estabelecer o que constitui o elemento próprio e particular de cada uma dessas formas.

Embora a descrição de Jolles não seja suficiente [para resolver satisfatoriamente a classificação dos géneros], a sua preocupação em ter em conta certas formas verbais, como o provérbio, o enigma, etc., abre novas vias ao estudo tipológico da literatura. Por outro lado, os géneros tão fixos como a fábula, o ensaio ou a lenda não se situam, sem dúvida, ao mesmo nível; mas o princípio pluridimensional de Jolles permite-lhe levar isso em conta. (DUCROT; TODOROV, 1991, p. 194).

Mais do que identificar e fixar uma nova forma nos Evangelhos é nosso objectivo levantar um problema concreto e tecer algumas considerações acerca da questão: A narrativa do Filho pródigo será uma verdadeira parábola, tal como é conhecida, ou a sua forma estará mais próxima do conto?

Há determinadas narrativas que pelas sua características sui generis flutuam na fronteira de dois géneros próximos, tornando-se difícil a sua classificação quanto ao género, suscitando divergências entre os autores que propõem a sua classificação ${ }^{2}$.

\section{0 conto}

É imperativo recordar que o conto tem a sua génese na tradição oral, tendo sido reconhecido do ponto de vista literário “como género narrativo já muito tardiamente, no início do século XIX, e aparecendo ancestralmente decorrente de circunstâncias socioculturais e pragmáticas que o condicionam de um ponto de vista técnico-formal" (GONÇALVES; MONTEIRO 2001, p. 31). Recordemos algumas dessas circunstâncias e suas implicações.

Gonçalves e Monteiro (2001, p. 31) lembram-nos que o relato do conto ocorria num ambiente comunitário, frequentemente ao serão. Para não enfadar os ouvintes, enveredando o contador por uma linearidade de acção, de forma a facilitar a comunicação da moralidade que se pretendia. Tal linearidade constrange

\footnotetext{
${ }^{2}$ Um caso concreto que tem suscitado a divergência entre os autores, quanto à classificação do género, diz respeito à obra Dama pé de cabra, publicada pelo autor, Alexandre Herculano, em Lendas e Narrativas (1851). A opção entre o conto e a novela é uma questão ainda em aberto.
} 
o contador a submeter-se a um conjunto de exigências formais como um tempo e espaço reduzidos e um número de personagens igualmente reduzido, de forma a possibilitar o empenho, por parte de um alocutário heterogéneo, na condução da acção; o efeito de catarse que se pretende no ouvinte é desta forma facilitado pela limitação de possibilidades de transferência emocional.

O conto é, por outro lado, motivado por factores sociais de ordem ideológico-conservadora em ordem a assegurar a continuidade da moral estabelecida; se por um lado a pragmática enunciativa supõe e exige uma brevidade discursiva, por outro a intencionalidade social reforça a mesma exigência através da eficácia sempre actuante a que o carácter breve do enunciado conduz.

O conto literário herdou algumas destas condicionantes e exigiu transposições sémio-discursivas. A primeira dessas transposições advém das características diferenciadas em que decorre o acto da enunciação. $\mathrm{O}$ contador transforma-se em contista e o ouvinte em leitor, exigindo esta transformação as adaptações decorrentes da configuração por parte do contista a determinados "modelos de escrita" e por parte do leitor a determinados "horizontes de espera". O modo literário que recebe e adapta o conto oral é o narrativo e o conto vai conviver com outros géneros deste modo. (GONÇALVES; MONTEIRO, 2001, p. 32).

Além disso, no conto literário, o autor recorre frequentemente à criação de processos estilístico-formais que facilitem ao leitor ter presente no seu horizonte visual os objectivos moralizadores do conto. O conto literário "aparece, desta forma, difícil de conceituar, devido à forma como foi inserido no modo narrativo" (GONÇALVES; MONTEIRO, 2001, p. 32).

Numa tentativa de delimitação temática, excluímos o conto moderno, ou seja, o conto do século XX, cujas características se afastam das do conto tradicional.

\section{A parábola}

Se percorrermos as páginas do Evangelho, particularmente as passagens que dizem respeito às parábolas, facilmente percebemos que se trata de narrativas cuja extensão sintagmática é brevíssima, ocorrendo a ação num tempo e num espaço 
concentrados, sempre com poucas personagens. O universo de imagens usadas nos relatos parabólicos, salvo raras exceções, encontra a sua origem no quotidiano dos seus destinatários: a imagem do semeador que lança a semente, que vê parte dessa semente ser comida pelas aves, outra pisada pelos transeuntes e uma terceira que germina, cresce e produz com abundância, é familiar aos ouvintes de Jesus (Lc 8, 4-8). O mesmo pode ser afirmado acerca da imagem do fermento que leveda a massa e da do joio que nasce no meio da boa semente, sem ser semeada (Mt 13, 2433), são imagens, entre outras, que fazem parte da mundividência dos contemporâneos de Jesus. Por isso, podemos afirmar que a vida nos aparece como ponto de partida do método das parábolas. Wielder (1971, p. 73) sublinha que o “carácter profundamente humano das parábolas se afasta da linguagem de iniciados, caracterizando-se esta pela secularidade, em oposição a uma linguagem esotérica e até religiosa”.

Dupont (1977) apresenta um estudo acerca das principais personagens que entram em cena nas parábolas, a saber: o rei, o juiz, o pastor e o pai. Cada personagem assume um comportamento pouco convencional, o qual contrasta com a maneira de ser, habitual, das figuras que representam.

Jeremias (1980) refere duas formas típicas usadas na apresentação das parábolas, quer de Jesus, quer dos seus contemporâneos: por um lado, refere as parábolas com começo em nominativo, onde não se pode falar, com rigor, em fórmula de introdução, trata-se de uma pura narrativa ${ }^{3}$. Refiram-se, como exemplo, as parábolas do capítulo XIII de Mateus, que são introduzidas pela

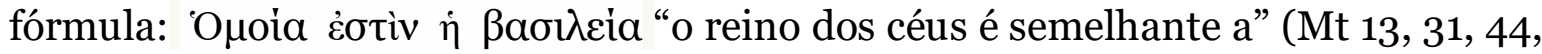
47), ou nos outros dois sinópticos, por fórmulas estereotipadas, seguidas do

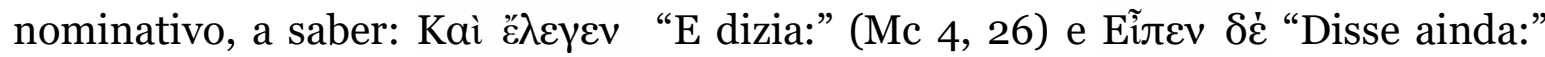
(Lc 15, 11). O vínculo entre o relato e os ouvintes a quem Jesus se dirige, nas parábolas com começo em dativo, realiza-se frequentemente pela mediação de uma pergunta, que normalmente aparece no início do relato (BEAUDE, 1988, p. 127):

\footnotetext{
${ }^{3}$ Mc 4,3 par.; 12,1 par.; Lc 7,41; 10,30; 12,16; 13,6; 14,16; 16,1.19; 18,2.10; 19,12; EvT 9 (grande banquete); 65 (os maus vinhateiros).
} 
“põe-se porventura a candeia debaixo do alqueire ou debaixo da cama?” (Mc 4,21); “a que havemos de comparar o reino de Deus?” (Mc 4,30; Mt 18, 12 par.); “ou qual é a mulher que tendo dez dracmas, se perde uma, não acende a candeia, não varre a casa e não procura cuidadosamente até a encontrar? (Lc 15, 8). A pergunta também pode ocorrer no final da parábola (DUPONT, 1977). Dessa forma, o interlocutor é diretamente interpelado pela força dominadora do dizer da pergunta retórica do parabolista cuja intenção retórica não visa qualquer ensinamento, mas tãosomente uma interpelação. Assim, a parábola dos dois devedores, a quem lhes foi perdoada a dívida, porque não tinham com que pagar, termina com a pergunta: “qual deles o amará mais?”(Lc 7, 42); ou a parábola do bom samaritano que interroga os destinatários, nestes termos: "qual destes três te parece ter sido próximo daquele homem que caiu nas mãos dos salteadores?” (Luc 10, 36). A interrogação aparece, assim, como "figura de pensamento pela qual se faz uma pergunta não para saber alguma coisa, mas para instar e intimar o que se diz. É adequada para excitar as paixões” (SZYMANIAK, 2000, p. 134).

\section{A narrativa do filho pródigo}

Quanto ao conto, na questão acima referida, o problema que se nos coloca, enquanto forma literária, diz respeito à dificuldade de precisar o género.

Se as tentativas em classificar os géneros e estabelecer as fronteiras entre o conto e a novela têm evidenciado dificuldades teóricas, no estabelecimento das premissas para uma definição, já o mesmo problema não se coloca em relação ao conto e à parábola. Há, todavia, uma narrativa - a do Filho pródigo -, que pelas suas características peculiares, mais claramente se nos assemelha a um conto do que a uma parábola. Não pretendemos tirar conclusões precipitadas; por isso, apresentamos um quadro sinóptico com as características das parábolas, da narrativa de Lucas e do conto: 


\section{Quadro 1- Quadro sinóptico}

\begin{tabular}{|c|c|c|}
\hline Parábola/características & Filho pródigo & Conto/características \\
\hline $\begin{array}{l}\text { Fórmula de introdução: } \\
\text { Em dativo (Interrogação) } \\
\text { Em nominativo (fórmula } \\
\text { estereotipada): o reino dos céus } \\
\text { é semelhante a... }\end{array}$ & $\begin{array}{l}\text { Fórmula de introdução: } \\
\text { Um homem tinha dois filhos... }\end{array}$ & $\begin{array}{l}\text { Fórmula de introdução: } \\
\text { Era uma vez... }\end{array}$ \\
\hline $\begin{array}{l}\text { Desfecho: } \\
\text { As parábolas possuem a } \\
\text { configuração de uma narrativa } \\
\text { aberta. }\end{array}$ & $\begin{array}{l}\text { Conclusão: } \\
\text { O Pai respondeu-lhe: Filho, tu sempre } \\
\text { estás comigo e tudo o que é meu é teu. } \\
\text { Mas tínhamos de fazer uma festa e } \\
\text { alegrar-nos, porque este teu irmão estava } \\
\text { morto e reviveu; estava perdido e } \\
\text { encontrou-se. }\end{array}$ & $\begin{array}{l}\text { Desfecho: } \\
\text { Os contos possuem um desfecho } \\
\text { conducente a uma estrutura } \\
\text { fechada, cujo selo podemos } \\
\text { reconhecer na conclusão. }\end{array}$ \\
\hline $\begin{array}{l}\text { Diálogo explícito entre } 0 \\
\text { narrador e os destinatários }\end{array}$ & $\begin{array}{l}\text { Ausência de diálogo entre o narrador e os } \\
\text { destinatários }\end{array}$ & $\begin{array}{l}\text { Os destinatários não participam } \\
\text { no diálogo }\end{array}$ \\
\hline $\begin{array}{l}\text { Função (Intenção retórica): } \\
\text { O parabolista pede a } \\
\text { assertividade do destinatário, } \\
\text { para este, através da reflexão, } \\
\text { chegar à mensagem, por si } \\
\text { mesmo. }\end{array}$ & $\begin{array}{l}\text { Função (Intenção retórica): } \\
\text { A resposta que o Pai dá ao filho mais } \\
\text { velho reveste-se de uma função } \\
\text { moralizante. } \\
\text { O destinatário não precisa de fazer } \\
\text { qualquer dedução lógica; a narração } \\
\text { persuade o destinatário. } \\
\text { Exemplo claro da arte de sugestão, } \\
\text { centrado sobre a representação do } \\
\text { episódio de um caso humano comovente. }\end{array}$ & $\begin{array}{l}\text { Função (Intenção retórica): } \\
\text { O conto reveste-se de uma função } \\
\text { pragmática; encerra sempre uma } \\
\text { certa moralidade. } \\
\text { Capacidade de seduzir o receptor }\end{array}$ \\
\hline Extensão: brevíssima & Extensão: 427 palavras & Extensão: (breve) Forma Simples \\
\hline $\begin{array}{l}\text { Espaço: } \\
\text { Concentrado }\end{array}$ & $\begin{array}{l}\text { Espaço: } \\
\text { Casa do pai e região longínqua }\end{array}$ & $\begin{array}{l}\text { Espaço: } \\
\text { Concentrado }\end{array}$ \\
\hline $\begin{array}{l}\text { Acção: } \\
\text { (simples) }\end{array}$ & $\begin{array}{l}\text { Acção: } \\
\text { Partida do filho mais novo, ausência, } \\
\text { regresso, festa, intriga (do filho mais }\end{array}$ & $\begin{array}{l}\text { Acção: } \\
\text { (simples, concentrada, linear) } \\
\text { Existe uma intriga }\end{array}$ \\
\hline
\end{tabular}




\begin{tabular}{|c|c|c|}
\hline & $\begin{array}{l}\text { velho) e conclusão (apologia do perdão). } \\
\text { A acção concentra-se ora em volta de } \\
\text { filho mais novo, ora em volta do pai; só } \\
\text { no final se concentra no irmão mais } \\
\text { velho. }\end{array}$ & \\
\hline $\begin{array}{lr}\text { Tempo: } & \\
\text { Velocidade } & \text { diegética } \\
\text { susceptível de } & \text { variação, } \\
\text { caracterizando-se geralmente } \\
\text { pela concentração. }\end{array}$ & $\begin{array}{l}\text { Tempo: } \\
\text { o passado e o futuro possuem um } \\
\text { significado menor ou nulo em relação ao } \\
\text { presente: "tínhamos de fazer uma festa e } \\
\text { alegrar-nos, porque este teu irmão estava } \\
\text { morto e [agora] está vivo; estava perdido } \\
\text { e [hoje] encontrou-se". }\end{array}$ & $\begin{array}{l}\text { Tempo: } \\
\text { Pode incluir um tempo diegético } \\
\text { alargado ou concentrado. } \\
\text { Normalmente é fracionado, em } \\
\text { conexão com a unidade de acção. }\end{array}$ \\
\hline $\begin{array}{l}\text { Personagens: } \\
\text { Poucos }\end{array}$ & $\begin{array}{l}\text { Personagens: } \\
\text { O Pai, o filho mais novo, o filho mais } \\
\text { velho e os criados (estes funcionam como } \\
\text { figurantes). } \\
\text { Presença das funções das personagens. }\end{array}$ & $\begin{array}{l}\text { Personagens: } \\
\text { Poucos } \\
\text { As personagens revestem-se de } \\
\text { funções }\end{array}$ \\
\hline
\end{tabular}

\section{Fonte: Elaborada pelos autores.}

A leitura sinóptica do quadro fornece-nos uma visão de conjunto, a partir da qual podemos facilmente apreender a proximidade da narrativa com o conto. Assim, começando pela curta extensão sintagmática - característica da grande maioria dos contos -, a narração de Lucas é formada, apenas, por 427 palavras; a expressão short story com que a língua inglesa designa o conto é sintomática desta característica que insere este tipo de literatura na narração curta. André Jolles (1972, p. 183) classificou-a como "forma simples".

A classificação da narrativa do Filho pródigo como parábola, quanto à extensão, é forçada; nenhuma parábola se aproxima dessa extensão; uma das maiores parábolas dos Evangelhos é a do Administrador infiel (Lc 16, 1-8), composta por 8 versículos e 176 palavras, ou seja, (33\%) da extensão da primeira. As outras parábolas são constituídas por três, quatro ou cinco versículos; as mais 
extensas poderão ultrapassar a do Administrador infiel, mas sempre muito inferiores, quanto à extensão, em relação à narrativa do Fỉlho pródigo.

A brevidade discursiva do conto, juntamente com outras características, que adiante referiremos, concorre com a intenção retórica do contista, para a "intenção moralizadora que caracteriza a narrativa, conferindo-lhe unidade de tom, já que tudo converge para um único objectivo, procurando causar uma determinada impressão junto do receptor da mensagem" (MONTEIRO, 1995, p. 36). Neste contexto, a narrativa lucana ilustra com bastante clareza o efeito intencional que se pretende produzir no destinatário; o fio condutor da história orienta toda a intriga para um desfecho moralizante. Por outro lado, nas parábolas, o parabolista pede a assertividade do destinatário, para este, através da reflexão, chegar à mensagem, por si mesmo.

Bloom (2001, p. 33) lembra-nos que “os contos não são parábolas, nem provérbios e não podem, portanto ser fragmentos. - e acrescenta - Exigimos deles o prazer da conclusão”. Notemos que as parábolas não têm conclusão4; são abertas, deixam o interlocutor a refletir nas interpelações do parabolista: "Quem tem ouvidos para ouvir, oiça” (Lc 8, 8; Mc 4, 9). Este é, sem dúvida, o principal argumento que nos leva a aproximar mais a narrativa do III Evangelista do conto do que da parábola.

Consideremos ainda outro aspecto - a fórmula de introdução, que condiciona a relação do narrador com o destinatário. Grande parte das parábolas começam com uma pergunta dirigida ao interlocutor: "a que havemos de comparar o reino de Deus?”(Lc 13, 18.20); noutras parábolas, a pergunta aparece no meio ou no fim: “Que vos parece, qual deles fez a vontade do pai?” (Mt 21, 31). Na parábola, o narrador interpela o destinatário; no conto (oral), o contador segue um fio condutor, com o qual prende a atenção dos ouvintes e os entretém. Eça de Queirós

\footnotetext{
${ }^{4}$ A narrativa do Administrador infiel (Lc 16, 1-8) e a "parábola" dos talentos (Lc 19, 12-27 e respetivo paralelo de Mt 25, 14-30) constituem duas exceções; em cada uma delas podemos encontrar uma conclusão: "os filhos deste mundo são mais sagazes do que os filhos da luz, no trato com o seu semelhante” (Lc 16, 8); “ A todo aquele que tem, dar-se-lhe-á, mas àquele que não tem, mesmo o que tem Ihe será tirado (Lc 19, 27). Estaremos, porventura, perante o embrião de um conto?
} 
faz referência a essa característica do contador, numa carta dirigida aos condes de Arnoso e de Sabugosa:

Foi um delicado prazer o ter-vos aqui, toda uma noite, ouvindo, ora a um, ora a outro, uma linda história bem sentida, real e no entanto poética, e contada com uma arte fina e sóbria. Positivamente, contar histórias é uma das mais belas ocupações humanas. (...) Todas as outras ocupações humanas tendem mais ou menos a explorar o homem; só essa de contar histórias se dedica amoravelmente a entretê-lo, o que muitas vezes equivale a consolá-lo. (...) Vós não sois desses: contais simplesmente, com elegância, o que observais com verdade: e por isso nos dais histórias vivas que deixam uma emoção viva. (QUEIRÓS, 1983, p. 342-343).

Finalmente, detenhamo-nos sobre as personagens. Numa primeira observação, registe-se que as personagens são "desprovidas de nome, tal como nos contos de fadas" (BETALHEIME, 1988, p. 55). Na narrativa de Lucas temos o pai, o filho mais velho, ofilho mais novo e os servos.

Consideremos, agora, as funções das personagens: Normalmente, os contos começam por referir uma situação inicial, onde se enumeram os membros da família. Apesar de Propp (2000) não considerar esta situação como função, definea como situação inicial: "Um homem tinha dois filhos (...)” (Lc14, 15). O mesmo autor refere que "os elementos constantes, permanentes, do conto são as funções das personagens, quaisquer que sejam estas personagens e qualquer que seja o modo como são preenchidas estas funções. As funções são as partes constitutivas fundamentais do conto" (PROPP, 2000, p. 60).

Isolemos as referidas funções das personagens, na narrativa evangélica, e notemos os pontos de encontro e desencontro com a proposta de Propp (2000):

1. Um dos membros da família afasta-se de casa (função: afastamento). $\mathrm{O}$ afastamento na narrativa evangélica aparece bem explícito, com a partida do filho mais novo: "Poucos dias depois partiu o filho mais novo [...]" (Lc15, 15);

2. Ao herói impõe-se a interdição (definição interdição). Esta função aparece implícita na consciência que o filho mais novo ganha da sua situação de miséria em relação à dos trabalhadores do seu pai: "Quantos jornaleiros de meu pai têm pão em abundância e eu aqui morro de fome!” (Lc 15, 17); 
3. A interdição é transgredida (definição: transgressão): "Vou partir, vou ter com meu pai e dizer-lhe: Pai pequei [...]" (Lc 15, 18);

4. O agressor tenta obter informações (definição: interrogação). "Uma nova figura aparece neste momento no conto; pode-se qualificá-la de agressor (de mau). O seu papel é perturbar a paz da família, provocar uma desgraça, fazer mal, causar prejuízo" (PROPP, 2000, p. 68). Esta função é desempenhada pela figura do filho mais velho, na medida em que reprova a atitude do pai face ao perdão concedido ao irmão mais novo: "Há já tantos anos que te sirvo sem nunca transgredir uma ordem tua e nunca me deste um cabrito para me alegrar com os meus amigos; e agora chegou esse teu filho que consumiu os teus bens com meretrizes, mataste-lhe o vitelo gordo" (Lc 15, 30).

A interrogação tem como "finalidade a descoberta de um local, ou de uma causa; em alguns casos encontramos a interrogação por pessoas interpostas” (PROPP, 2000, p. 68). Na narrativa de Lucas, a pergunta é feita a um funcionário do pai: “chamou um dos servos e perguntou-lhe o que era aquilo” (Lc 15, 26);

5. O agressor recebe informações sobre a sua vítima (PROPP, 2000, p. 68). "Disse-lhes ele: $O$ teu irmão voltou e teu pai matou o vitelo gordo, porque chegou são e salvo" (Lc 15, 27);

6. O agressor tenta enganar a sua vítima para se apoderar dela ou dos seus bens (definição: engano) No texto evangélico, o agressor age pela persuasão: Há tantos anos que te sirvo sem nunca transgredir uma ordem tua e nunca me deste um cabrito para me alegrar com os meus amigos" (Lc 15, 29);

7. A vítima deixa-se enganar e ajuda assim o seu inimigo sem o saber (definição cumplicidade). No Filho pródigo, esta função não se verifica, pois o pai não se deixa enganar. A partir deste momento (função 7), as funções propostas por Propp (2000) deixam de se verificar no texto de Lucas. 
Há outras narrativas evangélicas5 que pelas suas características se assemelham à do Filho pródigo. Podemos assim identificar a do Administrador infiel (Lc 16, 1-8) e a narrativa dos Vinhateiros homicidas (Lc 20, 9, 19), a das Moedas de ouro (Lc 19, 11-27 e respectivo paralelo de Mt $(25,14)$, que se revestem de característica muito semelhantes às do Fỉho pródigo, apesar de muito menos desenvolvidas. Caracterizámo-las como embriões de contos.

Dispensamo-nos de fazer a análise destas passagens, mas a semelhança, quanto à estrutura, das referidas narrativas, permite-nos aproximá-las mais do conto do que das características das parábolas.

\section{Conclusão}

Desta análise, deduzimos que Jesus foi um verdadeiro contador de histórias. O conto, pelo menos em forma embrionária, foi seguramente um instrumento usado por Jesus para fazer passar a mensagem do reino; os evangelistas não foram tão exímios contistas, mas, pelo menos, Lucas soube consignar na literatura evangélica a memória de um verdadeiro contador de histórias. Na narrativa do Filho pródigo, encontramos as propriedades configuradoras da sua individualização como género da seguinte forma: a conclusão moralizante de uma história fechada, com princípio, meio e fim, que cerra ao leitor os caminhos que o possam levar a enveredar por interpretações arbitrárias, a concentração de espaço, tempo e reduzido número de personagens, bem como a curta extensão sintagmática, mas sempre extensa comparada com a das parábolas, colocam-nos perante um verdadeiro e extraordinário conto.

\footnotetext{
${ }^{5}$ Vejam-se as passagens de Lc $(19,12-27)$ e respetivo paralelo de Mt $(25,14-30)$ (Parábola das minas) e a de Lc (16, 1-8) (Administrador infiel), onde se podem encontrar uma estrutura muito semelhante à do Filho pródigo.
} 


\section{REFERÊNCIAS}

BEAUDE, P-M. Jesús de Nazaret. Estella: Editorial Verbo Divino, 1988.

BETALHEIME, B. Psicanálise dos contos de fadas. Venda Nova: Bertrand Editora, 1988.

BLOOM, H. Como ler e porquê. Lisboa: Caminho, 2001.

BRONCKART, J. P. Atividade de linguagem, textos e discursos: por um

interacionismo sócio-discursivo. São Paulo: EDUC, 2003.

DIBELIUS, M. La história de las formas evangelicas. Valencia: EDICEP, 1984.

DUCROT, O.; TODOROV, T. (Org.). Dicionário das ciências da linguagem. Lisboa: Publicações D. Quixote, 1991.

DUPONT, J. Pourquoi des paraboles. Paris: Seuil, 1977.

GONÇALVES, H.; MONTEIRO, M. A. Introdução à leitura de contos de Eça de Queirós. Coimbra: Almedina, 2001

HERCULANO, A. Lendas e narrativas. Lisboa: Imprensa Nacional; Viúva de Bertrand e Filhos, 1851.

JEREMIAS, J. As parábolas de Jesus. São Paulo: Edições Paulinas, 1980.

JOLLES A. Formas simples. Paris: Edition du Seuil, 1972.

MONTEIRO, M. A. M. Génese e escrita do conto no diário de Miguel Torga. Vila Real, 1995. 52 f. Tese (Doutoramento em Literatura Portuguesa Contemporânea) Departamento de Letras, Artes e Comunicação, Universidade de Trás-os-Montes e Alto Douro.

PROPP, V. Morfologia do conto. Alpiarça: Veja, 2000.

QUEIRÓS, E. Correspondência. Lisboa: Imprensa Nacional - Casa da Moeda, 1983.

RAIMOND, B.; FITZMYER, J.; MURPHY, R. Comentario bíblico San Jerónimo. Madrid: Ediciones Cristandad, 1972.

SZYMANOAK, W. J. Dicionário de ciências da comunicação. Porto: Porto Editora, 2000.

TODOROV, T. Os géneros literários. Lisboa: Edições 70, 1978. 
WILDER, A. N. Early christian rhetoric. The language of the gospel. London: Mac Millan, 1971.

BÍBLIA DE JERUSALÉM. São Paulo: Edições Paulinas, 1993.

NOVO TESTAMENTO GREGO: Westcott-Hort (1881). Sociedade bíblica do Brasil, 2007. Disponível em:<http://www.sbb.org.br.> . Acesso em: 15 nov. 2017. 